\title{
The Most Successful Business Model of Mobile Applications: A Comparative Analysis of Six Iranian Mobile Games
}

\author{
Sina Baghbaniyazdi*, Hamed Ferdosara \\ University of Tehran, Tehran, Iran. \\ * Corresponding author. Tel.: +98 935255 9135; email: sina.baghbani@ut.ac.ir \\ Manuscript submitted September 10, 2016; revised December 23, 2016. \\ doi: 10.17706/jsw.12.3.201-211
}

\begin{abstract}
While recent literature has partly advanced our understanding of mobile application business models, less attention has been given to identify the most successful business model especially in the game area. In this vein, this paper presents a comparative analysis of six Iranian android games in an app store "Iran Apps" which were top level games in terms of download and rate during a 3-month study. The results reveal that freemium and In-app purchase models were more successful, while advertising model can be efficiently used as a complementary model. This provides valuable insight into why some mobile applications are more successful than others.
\end{abstract}

Keywords: Business model, mobile applications, mobile games Iran.

\section{Introduction}

Mobile app market is booming. According to Gartner (2013), in 2012, the amount of annual mobile application downloading around the world has reached 64 billion, creating 18 billion dollars revenue for developers. This is predicted that the mobile apps downloads will increase to 268.7 billion per year by 2017 [1]. Moreover, according to the statistics by Newzoo in 2015, Iran by earning 194 million dollars in gaming sector ranked at the third place in the Middle East While only half of the Iranian have access to the internet and about a quarter of them use smartphones which would be a great opportunity for developers to monetize in mobile gaming industry [2]. However, less attention has been given to the business models of mobile applications.

In recent years, various definitions of business model are presented [3], [4]. Some of them has focused on factors related to offering market and competitive strategy factors [5], while most of them have paid attention to components such as business core logic, value creation, value proposition, target customers, distribution channels and cost structures [6], [7], [8]. According to Chesbrough (2006), concept of business model describes as "a guideline for how a network of organizations cooperates in creating and capturing value from technological innovation" [9]. Unfortunately, there is little academic research in the field of mobile application business model especially mobile gaming. To this end, the literature has identified 6 types of business model: free, premium, freemium, In-app purchase, In-app advertising and combination model [10], [11].

To address this gap, this study adopts a qualitative comparative analysis of the business models of 6 Iranian mobile games compliance with the six business models discussed in the literature. Each of them during the 3-month study was among the top level mobile games in an Iranian app store "Iran Apps". 
Findings illustrate that freemium and In-app purchase models in terms of download and rate and consequently revenue are much more suitable for developers. This paper makes at least two important contributions to the literature of mobile application. First, we attempt to identify the most successful business model of mobile applications. Moreover, while there is less empirical research in the mobile gaming section and developing contexts, we design a qualitative comparative analysis in the developing context of Iran to identify the best revenue model of mobile games.

The rest of this paper is structured as follows: We first present a literature review in the subsequent section, followed by the research methodology. Finally, the results and conclusions will be discussed.

\section{Literature Review}

\subsection{Mobile Applications}

A mobile application is software designed to run on smart phones, tablets and other mobile devices [12]. The purpose of these applications is interacting with users, especially in the case of games and are more like a computer program than a website [13]. These applications are available for free as well as paid. There are also applications that are available for free at first, further benefits and options are conditional on payment [14]. Approximately, between $20-30 \%$ of these applications' monetary income is allocated to distributers and the remainder will be allocated to the developers [15].

In recent years, different mobile companies are making their smartphones. With increasing the computing power of these mobile phones, the number of mobile applications around the world has increased. The use of smart phones is growing rapidly in both developed and developing countries [16].

Some analysts believe that before the arrival of iPhone in 2007, users were not able to experience the performance of personal computers as much as handheld devices. These new phones are called "smart phones" and their relationship with their associated software is increasingly widespread in daily life. Moreover, Google in 2008 with its platform, Android, entered the market [17]. In practice, applications of IOS devices are taken from "Apple store" and the applications of Android devices are taken from "Google play" which formerly was called "Android Market". There are around currently 1.2 million apps in the Apple Store, and about 1.4 million apps available in Google Play [18]. In addition, other players in this market such as Rim, and Nokia's are rapidly entering this market. Research conducted by IDC, predicts that the market for mobile applications is still expanding such that it is expected that applications downloaded from 10.9 billion in 2010 to increase to about 76.9 billion in 2015. In addition, there will be a Mobile applications income growth worldwide, more than $\$ 35$ billion in 2014 [19].

There are mainly two main types of mobile applications: Native and web based. "Native apps" are available for download directly from markets of mobile applications, which are more like the personal computer software in terms of hardware. The main advantage of these applications is that they can be used in the absence of the Internet. On the other hand, "web apps" are apps that directly benefit from an online interface like a website [20]. Some applications are also hybrids which typically combine the interface and coding components of a web-based interface with the capabilities derived from native applications. This will help developers to update their using applications remotely [21].

There are twelve categories of mobile business applications [22]. The classifications are as follows: 1) Mobile financial applications (banking and payment), 2) Locating and purchasing orders, 3) Mobile entertainment services (video and similar services). However, these categories only belong to mobile business applications (mobile applications, including the trading of goods and services). In addition, according to the report by Ramsay \& Nielsen, the authors have divided the mobile applications into two groups: 1) highly goal-driven and 2) entertainment. Highly goal-driven applications deal with providing fast answers to specific questions, while entertainment applications help users to causally pass time [23]. In summary, the benefits of apps classification can be divided as follows: 1) To obtain a set of customization 
instructions for specific application, 2) Using previous experience to develop new applications of the same type [24].

\subsection{Mobile Games}

Mobile games are played on mobile phones, smartphone, tablets, laptops and other devices [25]. Before the dawn of smartphones, mobile gaming occurred on handheld devices such as Nintendo DS or Sony PSP. However, nowadays using smartphones for gaming has become common and hundreds of low priced games with high quality graphics are available. In fact, the first game inside the mobile phones was Tetris in 1994, although it was not until 2000 when the first downloadable game was introduced for a mobile phone [10]. Meanwhile, the applications where we can download were not launched until 2008, with the appearance of Apple App Store with IOS. Emergence of these apps changed the mobile gaming way and opened a new market for mobile markets [26].

Today, games are the most popular category in mobile app stores [27], [28] and this created a new border for app developers. Apple's IOS and Google's Android operation systems have the capability of running many high-quality games. As a result, Nintendo's and Sony's handheld devices are quickly replaced by smartphones. In 2009, the IOS and Android revenues from mobile gaming stood at \$500 million. By 2010, these revenues reached to $\$ 800$ million, and continued to climb in 2011 when they hit $\$ 1.9$ billion, representing the growth of using mobile gaming in the digital world [29].

In addition, according to neo-mobile Company (2014), the continued growth of mobile games and entertainment products in the entertainment industry of mobile is expected to bring 65 billion revenue in 2016 [30]. Similarly, according to a study by Millennial Media and ComScore, the entertainment industry with a share of $47 \%$ of the market hold the leadership of buying smartphones digital products. These purchases include many products such as movies, music videos and digital books. Moreover, the Statistics of two mobile application marketplaces (Apple store, 2015; Google Play, 2016) show the importance of this category. In the Apple store, the applications of 1) Game (22.49\%), 2) business (10.38\%) and 3) education (9.44\%), are the three most popular respectively. In the Google Play market, the applications of 1) educational (around 156,000 apps), 2) lifestyle (about 141.000), 3) Entertainment (about 135,000) are the three most popular [27], [28].

Taken together, according to Jeong and Kim (2009) mobile games can be summarized in three concepts. Portability, accessibility, networkability and simplicity. These features point to this reality that mobile games can be played anytime and in anyplace and the considerable point is their easy learning. Furthermore, networkability feature points to the social network games revolution. These games could be connected and synchronized in different platforms [31].

\subsection{Business Model}

Historically, according to Osterwalder et al (2005) the term business model was used first time in an academic article in 1957 and in a paper in 1960 [32]. However, the importance of this concept finally took off in the 1990s, when it identified as a concept for shifting from traditional to digital business [33]. Since then, it became quite popular in both academic and business world [6].

In fact, the term business model was one of the most frequently used words in Internet boom-bust cycle during 1998-2000. In most business model definitions in the 1990s, we can assume that business model describes as the business logic behind the value creation of a specific product or service [34].

Business model is a rather wide concept in scientific studies. During the 1970s, the business model was mainly used to describe IT-related business processes [35]. Recently, it has been used for analyzing market structures and strategic choices related to positioning of organizations within markets [4], [36]. In addition, according to Zott et al, this concept is used for three phenomena. 1) E-business and usage of information 
technology in organizations, 2) strategic issues, 3) technology and innovation management [42]. Morris et al (2005), on the other hand, consider other business aspects and identify three different approaches (1) economic, (2) operational and (3) strategic [37].

Overall, according to Morris et al (2005) business model framework comprises six main components assessing value proposition, customers, internal competencies, competitive strategy, revenue logic and factors for future such as scope, and the size of the organization [5]. Furthermore, Shafer et al (2005) definition consists four key terms: business core logic, strategic choices, value creation, and lastly value network [6].

\subsection{Mobile Applications Business Model}

Business model is the story of a company explaining how the company works [38]. Also, the business model assists with company structure to reaching goals. Furthermore, as business models are variable, the companies can adapt their business model with market conditions [39].

In the same vein, as app store revenues come from sharing application provider revenues, they allow developers to adopt different business models [40]. When comparing different mobile application categories, games have the widest range of revenue models [41]. In general, business models can be classifies within 6 categories based on mobile application literature [10], [42], [11], [29].

\subsubsection{Premium}

Logic of this model is very easy to understand. App store charges the end user for downloading and installing the app via a one-off purchase and then it pays developers their revenues and keep its share. The prices of paid apps varied across countries. From January 2012 to January 2014, the average prices were US\$0.99 to US\$1.99 in Australia, South Korea, Canada, Germany, the United States, the United Kingdom, France, Russia and China, while paid apps in Japan were relatively more expensive, priced at around US $\$ 18$ [43].

\subsubsection{Free}

In this model, developers offer the app free of charge to users. This business model is the most widely used model in the world of apps and raises the chance of the app downloading. Gartner forecasts that about 127 billion downloaded apps will be free in 2014 , namely over $90 \%$ of all downloads [1]

\subsubsection{Freemium}

This model is as same as free model. However, if a user wants to have an even better experience, then they have to pay for it. This model is essentially a combination of free and premium models. Freemium models are common in games categories because no upfront download fee is charged, so as to entice a larger number of users [44].

\subsubsection{In-app purchase}

In-app purchase (IAP) is a variation on the Freemium model. But rather than a single upgrade to the premium version, you offer individual features such as higher levels in games or upgrading to the full version directly within the games [45].

\subsubsection{In-app advertising}

In this model, the games are freely offered to users while developers provide advertisements for other products or services to earn money. The most common in-app advertising models could be defined as banner ads, videos, offer walls and interstitials. For instance, gaming apps may ask players to watch an advertisement in exchange for virtual game currency. Generally speaking, the revenue generated by in-app advertising showed a growth of 56\% from 2013 to 2014 [46]. 


\subsubsection{Combination model}

In this model, a combination of different business models regarding the highest profit and market conditions would be applied by developers. Freemium model plus In-app Advertising and IAP model with premium identify as the most important combination models.

However, the information and internet industries have always been involved in business model issues due to they are often difficult to price, and users have many ways to get them without paying. Thus, figuring out a model to earn revenues from users/customers is key factor in design of business model in these industries [38].

Overall, while the literature has advanced our understanding of mobile application business models, less consideration has been given to the analysis of the most successful business models in mobile gaming. In particular, less is known about these factors in the context of developing countries, where mobile applications are gaining increasing popularity. This paper aims to examine 6 successful mobile games adopting different business models in line with existing literature to advice and guide professionals as well as who are interested in this field.

\section{Methodology}

This study aims at identifying the most successful business models of mobile games across the common application business models in Iran. Regarding the limitation knowledge on literature in this area, we deliberately adopt an exploratory research method. So our focus will be on gathering proposition rather than testing hypothesis. According to Yin (1984) and Ragin (1987), we adopt a comparative case analysis design to explore the best business model of mobile apps [47], [48].

Accordingly, the selection of cases was based on the following criteria. First, the chosen games had to be widely recognized as successful games in an Iranian app store "Iran Apps" during the study from 12/2015 to $02 / 2016$. Second, each of them had applied one of the 6 common business models. Lastly, priority was given to the games which had the highest rate and download.

Furthermore, in order to strength the results, we gathered data from different sources: existing case studies, personal interviews with founders and organizational members as well as internet sources. Eventually, data allowed us to analyze different business models and compare across cases.

Although we are aware of the limitations of our sampling and data analysis, we consider this study as the first important step for future empirical research. In the next section we provide a detailed review of the six cases.

\subsection{Six Successful Mobile Games}

\subsubsection{Rooster wars (In-app purchase and Advertising)}

This game was first released in 2013 in Iran market. The Developer of this popular game is Medric game studio which is one the most successful studio in Iran. This game in Iran Apps android marketplace during the study has been downloaded about 80,000 by users. The Rate of the game is 4.5 as well. It is worth noting this game classifies within action category and for more than one year has been identified as the best-selling mobile game in Iran android market.

\subsubsection{Pocket army (in-app purchase)}

The game was produced by Simiya world game studio which could be rated in the top 10 games of all marketplaces and three top level games in Iran Apps market shortly after launch. The game is placed in Strategy category, which is the most popular category among Iranian users. Rate of this game in Iran Apps market was 4.6 and has been downloaded 40,000 during the review. It should be noted that this game has entered the Iran market in 2014. 


\subsubsection{Hados (Premium)}

This game entered Iran markets in 2014. However, having stunning graphics could not achieve a worthy position. During 3-months study, the number of the download was approximately 430. This game was also shared freely after a while. Rate of this game is 4 as well. Freelance developer of this game has classified it within adventure category.

\subsubsection{Viraj (freemium)}

Viraj game could be known as the first racing game in Iran. The idea of the game is very similar to Traffic Racer but not its imitation. The good features can be seen in the game, while can be defined as the most complete mobile game in racing category in Iran. In fact, this game was published in 2011 by NOA Games studio. This game uses freemium business model and has always been one of the most popular android games in Iran Apps. Also, it had been downloaded about 70,000 and rated 4.6 during the study.

\subsubsection{Jealous chickens (free)}

This game is completely free and without any advertising was released independently in 2014. The rate of the game was 4.4 in Iran Apps market and had been downloaded 10,000 during the 3-month review. It should be noted that it is placed in arcade category.

\subsubsection{Pijamas (In-app advertising)}

The game is the collaboration of Ferfereh and Boomerang game studios and was published for free in 2015. It should be noted that this game uses In-app advertising business model. Furthermore, during the study the rate of the game was 4 and has downloaded nearly 10,000. It is also classified within casual games.

\section{Findings}

All 6 analyzed games identified as the most successful mobile games in an Iranian app store "Iran Apps" during the study while each of them had applied different types of business models. Table 1 summarizes the statistics of reviewed mobile games, extracted from our data collection and analysis.

Table1. Six Mobile Games' Background

\begin{tabular}{|c|c|c|c|c|c|c|}
\cline { 2 - 7 } \multicolumn{1}{c|}{} & Rooster wars & $\begin{array}{c}\text { Pocket } \\
\text { Army }\end{array}$ & Hados & Viraj & $\begin{array}{c}\text { Jealous } \\
\text { chickens }\end{array}$ & Pijamas \\
\hline Release date & 2013 & 2015 & 2015 & 2011 & 2015 & 2015 \\
\hline Category & Action & Strategy & Adventure & Racing & Arcade & Casual \\
\hline $\begin{array}{c}\text { Business } \\
\text { model }\end{array}$ & $\begin{array}{c}\text { Combination } \\
\text { (IAP \& } \\
\text { Advertising) }\end{array}$ & $\begin{array}{c}\text { In-app } \\
\text { purchase }\end{array}$ & Premium & Freemium & Free & $\begin{array}{c}\text { In-app } \\
\text { advertising }\end{array}$ \\
\hline Downloads & 80,000 & 40,000 & 430 & 70,000 & 10,000 & 10,000 \\
\hline Rate (1-5) & 4.5 & 4.6 & 4 & 4.6 & 4.4 & 4 \\
\hline \hline
\end{tabular}

Findings of the study indicated that freemium model and its sub-category namely In-app purchase were by far the most successful business models of mobile games in the context of Iran in terms of download and rate (Pocket Army 40,000 and Viraj 70,000 downloads), while premium and free models (Jealous chickens and Hados with 10,000 and 430 downloads respectively) have lost their position among users and In-app advertising model is also suitable to consider as a complementary model (Rooster wars 80,000 downloads) especially at the time of market saturation as well as decreasing user adoption and will not be effective 
independently (Pijamas 10,000 downloads).

As mentioned earlier, little has been done to identify the most successful business model of mobile applications especially in mobile gaming sector. For example, Hernández \& Volter (2014) considers freemium model as the best one and Liu et al. state that a 'freemium strategy' is not only a financial model but also a marketing approach at the same time [49]. Furthermore, by switching over to the freemium paradigm the developers wouldn't have to bother with having to develop a free- version and a professional version of the application. Instead, the application will be free to download, and the user himself can decide what he wants purchase in form of additional features or new content [45]. On the other hand, Australian Communications and Media Authority (2011) considers In-app purchase as an appropriate business model [50]. Moreover, basic evidence shows that in-app purchase has been quite successful in App Store, and it has reached large popularity in Google Play as well [51]. Some authors also point out that the combination of freemium and In-app purchase is the best model of mobile gaming to monetize [52]. In general, Seufert (2014) points out that combining IAP or freemium with other kinds of models such as advertising could be the best and most effective way to obtain revenue from all users [53].

\section{Learning Points and Conclusion}

The present study was intended to identify the most successful mobile application business model in mobile gaming area. In this vein, it examined the business models of six successful mobile games in a 3month period: Rooster wars, Pocket army, Hados, Viraj, Jealous chickens and Pijamas which are widely recognized as successful games in terms of download and rate in an Iranian mobile app store "Iran Apps". The results of the study showed that fermium and IAP models are the best methods to monetize for Iranian app developers. It should be noted that many developers after market saturation and consequently the reduction of user acceptance, would use In-app advertisement models especially banner ads and videos as the complementary model. The latest results of this research are shown in table 1. Similarly, App Annie, a leading provider of app ranking data and high quality mobile analytic (2013) reported that freemium apps "free apps that have in-app purchases" are experiencing impressive revenue growth worldwide, far outpacing premium apps in both IOS and Google Play. Moreover, it estimated that revenues for freemium apps in 2012 on IOS have more than quadrupled while it grew 3.5X on Google Play. It worth noting Premium revenues for both app stores remained relatively flat in these time periods [54]. Furthermore, statistics illustrate that premium apps represent about $24 \%$ of Apple App Store revenues. Additionally, it is reported that 4 of 5 premium apps in Google Play are downloaded less than 100 times [52].

In addition, recent research of Distimo (2013) demonstrated that use of IAP is increasing. In February 2013, for example, 76\% of all Apple App Store revenue in the U.S. was generated using in-app purchases. While the figure was higher in Asian markets, with over $90 \%$ of revenues coming from IAP. On the other hand, some believes that free apps are continuing to dominate the market, so it is clear that mobile advertising should be at the top of developer list. Indeed, Gartner forecasts that about 127 billion downloaded apps will be free in 2014, namely over $90 \%$ of all downloads [1]. As mentioned earlier, less attempt has been made to provide a comprehensive research in the field of mobile applications business models, particularly for game applications [43], [52].

In sum, this paper contributes to the growing literature of mobile application in two ways. First, from a theoretical perspective, while previous studies on mobile applications mainly focused on the definition of business models, this study addresses the most successful business model of mobile application especially in the field of mobile gaming. Moreover, the discussion of mobile applications is growing rapidly in developing countries such as Iran, and little effort has been made to investigate these models in such contexts. Second, from a practical perspective, it hopes to provide valuable insights for both mobile 
application developers and marketers aiming to enhance their app performance.

Finally, like other studies this research has limitations and challenges providing opportunities for future research. First, as the findings of this study have been obtained using a qualitative comparative analysis, the results lack statistical generalizability. Future research can address this limitation by quantitatively testing our results and propositions. Second, we limited our analyses to the game category, restricting our findings to this sector. Testing our results in other mobile application categories can be a worthwhile avenue for future research. Overall, we hope that the findings of this study can be considered as a guideline for application developers, managers and game makers especially in the field of games and stimulate future empirical research that builds on these findings.

\section{References}

[1] Gartner. (2013). Gartner says mobile app stores will see annual downloads reach 102 billion in 2013. Retrieved November 10, 2015, from: www.gartner.com/newsroom/id/2592315

[2] Newzoo. (2015). Top 100 countries by game revenues. Retrieved November 15, 2015, from: http://nwezoo.com/insights/rankings/top-100-countries-by-game-revenues

[3] Amit, R., \& Zott, C. (2001). Value creation in e-business. Strategic Management Journal, 22(6-7), 493520.

[4] Chesbrough, H. W. (2003). Open Innovation: The New Imperative for Creating and Profiting From Technology. MA: Harvard Business Press.

[5] Morris, M., Schindehutte, M., \& Allen, J. (2005). The entrepreneur's business model: Toward a unified perspective. Journal of Business Research, 58(6), 726-735.

[6] Shafer, S. M., Smith, H. J., \& Linder, J. C. (2005). The power of business models. Business horizons, 48(3), 199-207.

[7] Osterwalder, A. (2004). Understanding ICT-based business models in developing countries. International Journal of Innovation and Technology and Management, 3(2-4), 333-348.

[8] Osterwalder, A. \& Pigneur, Y. (2010). Business Model Generation - A Handbook for Visionaires, Game Changers, and Challengers. New Jersey: John Wiley \& Sons, Inc.

[9] Chesbrough, H. W. (2006). Open Business Models: How to Thrive in the new Innovation Landscape. MA: Harvard Business School Press.

[10] Hernández, M. G., \& Volter, M. (2014). Incremental digital product Innovation in social mobile games: A case study of King Digital Entertainment. Department of informatics Master's program in IT Management.

[11] Müller, R. M., Kijl, B., \& Martens, K. J. (2011). A comparison of inter-organizational business models of mobile app stores: There is more than open vs. closed. Journal of Theoretical and Applied Electronic Commerce Research, 6(2), 63-76.

[12] Inukollu, V., Keshamoni, D., Kang. K., \& Inukollu, M. (2014). Factors influencing quality of mobile Apps: Role of mobile App development life cycle. International Journal of Software Engineering and Applications, 5(5), 15-34.

[13] Kubadia, V., (2013). Mobile web VS Mobile Apps. Retrieved November 10, 2015, from http://www.slideshare.net/vaibhavkubadia75/mobile-web-vs-mobile-apps

[14] Dave, W., \& Schneider, M. (2010). The business of iPhone app development: Making and marketing apps that succeed.

[15] Siegler, M. G. (2008). Analyst: There's a great future in iPhone apps. Retrieved December 8, 2015, from http://venturebeat.com/2008/06/11/analyst-theres-a-great-future-in-iphone-apps

[16] Islam, M., Islam, M., \& Mazumder, T. (2010). Mobile application and its global impact. International 
Journal of Engineering and Technology, 10(6), 72-78.

[17] Hermansson, C. (2013). The Difficulties in Developing Useful Mobile Applications Guidelines for App Developers in Cross Media Platforms. Department of Informatics, Umea University.

[18] Business insider. (2013). The Year Ahead in Mobile. Retrieved September 22, 2015, from http://www.businessinsider.com/2013--the-year-ahead-in-mobile-slide-deck-2013-12

[19] Uskov, V. L. (2013). Mobile Software Engineering in Mobile Computing Curriculum. paper presented at interdisciplinary Engineering Design Education Conference (IEDEC).

[20] Wong, S. H. R. (2012). Which platform do our users prefer: website or mobile app? Reference Services Review, 40(1), 103-115.

[21] Evans, B. (2011). Industry innovations: A mobile applications interview with Bob Evans. Retrieved November 23, 2015, from http://www.jiops.com/01/2011/industry-innovations-a-mobileapplications-interview-with-bob-evans

[22] Varshney, U., \& Vetter, R. (2001). A framework for the emerging mobile commerce applications. Proceedings of the 34th Annual Hawaii International Conference in System Sciences.

[23] Ramsay, M., \& Nielsen, J. (2000). WAP usability deja vu: 1994 all over again. Nielsen Norman Group. Report from a field study in London, Nielsen Norman Group, Fremont, CA, USA.

[24] Spataru, A. (2010). Agile Development Methods for Mobile Applications. School of Informatics University of Edinburgh.

[25] Novak, J. (2011) Game Development Essentials: an Introduction. New York: Cengage Learning.

[26] The mobile game arch project. (2013). The future of the European mobile game ecosystem. Retrieved December 10, 2015, from European Games Developer Federation: http://cordis.europa.eu/docs/projects/cnect/2/288632/080/publishing/readmore/MGAfinalbrochur e.pdf

[27] Statista. (2015). Most popular apple app store categories in December 2015, by share of available apps. Retrieved December 18, 2015, from http://www.statista.com/statistics/270291/popular-categoriesin-the-app-store

[28] Appbrain. (2016). Most popular Google play categories. Retrieved December 18, 2015, from http://www.appbrain.com/stats/android-market-app-categories

[29] Rakestraw, L., Eunni, V., \& Kasuganti, R. (2013). The mobile apps industry: A case study. Journal of Business Cases \& Applications, 9(1), 1-39.

[30] Neomobile. (2014). Mobile entertainment: From ringtones to apps and video streaming services for cartoons. Retrieved December 11, 2015, from http://www.neomobile-blog.com/wpcontent/uploads/2014/03/mobile-entertainment-cartoons-feature-films-rainbow-toons-01.pdf.

[31] Jeong, E., \& Kim, D. (2009). Definitions, key characteristics, and generations of mobile games. In D. Taniar (Ed.), Encyclopedia of Mobile Computing and Commerce, 185-189.

[32] Osterwalder, A., Pigneur, Y., \& Tucci, C. L. (2005). Clarifying business models: Origins, present, and future of the concept. Communications of the Association for Information Systems, 16(1), 1-25.

[33] Jones, G. M. (1960). Educators, electrons, and business models: A problem in synthesis. Accounting Review, 35(4), 619-626.

[34] Magretta, J. (2002). Why business models matter. Harvard business review, 80(4), 86-93.

[35] Konczal, E. F. (1975). Models are for managers, not mathematicians. Journal of Systems Management, 26(1), 12-15.

[36] Porter, M. E. (2001). Strategy and the internet. Harvard Business Review, 79(1), 63-76.

[37] Zott, C., Amit, R. \& Massa, L. (2011). The business model: Recent developments and future research. Journal of Management, 37(4), 1019-1042. 
[38] Teece, D. J. (2010). Business models, business strategy and innovation. Long range planning, 43(2), 172194.

[39] Ojala, A., \& Tyrvainen, P. (2011). Developing cloud business models: A case study on cloud gaming. IEEE Software, 28(4), 42-47.

[40] Gans, J. (2012). Mobile application pricing. Information Economics and Policy, 24(1), 52-59.

[41] Heikkinen, L. (2013). Business Model Analysis on Android App Stores. (Master's thesis), University of Jyväskylä, Information Systems.

[42] Froberg, P. (2012). Freemium 101, a brief introduction to the freemium business model. Retrieved September 20, 2015, from: http://www.freemium.org/wp-content/ebook-101.pdf.

[43] Distimo, (2014). How the most successful apps monetize globally. Retrieved January 20, 2016, from http://www.distimo.com/download/publication/Distimo_Publication_-_February_2014/EN/archive

[44] Tang, A., (2016). Mobile app monetization: App business models in the digital era. International Journal of Innovation, Management and Technology, 7(5), 224-227.

[45] Haines, J. H., \& Hanssen, A., (2013). In-Application Payment from Mobile Apps A study of In-App Payment (Master's thesis), Department of Computer and Information Science, Norwegian University of Science and Technology.

[46] IDC \& App Annie, (2014). Mobile app advertising and monetization trends 2012-2017: The economics of Free-slide. Metrieved March 12, 2016, from https://s3.amazonaws.com/files.appannie.com/reports/App_Annie_and_IDC_Mobile_App_Advertising_ and_Monetization_Trends_2012-2017

[47] Yin, R. K. (2013). Case study research: Design and methods. Sage, Thousand Oaks, CA.

[48] Ragin, C. C. (1987). The Comparative Method: Moving Beyond Qualitative and Quantitative Strategies. Berkeley: University of California Press.

[49] Liu, C., Au, Y., \& Choi, H., (2012). An empirical study of the freemium strategy for mobile apps: Evidence from the Google play market. Proceedings of the 33rd International Conference on Information Systems.

[50] Australian communications and media authority. (2011). Emerging Business Models in the Digital Economy-The Mobile Applications Market. Retrieved November 20, 2015, from http://www.acma.gov.au/webwr/_assets/main/lib310665/emerging_business_models.pdf

[51] ABI Research, (2012). In-app purchase to outpace pay-per-download revenues. Retrieved January 11, 2016, from www.abiresearch.com/press/in-app-purchases-to-outpace-pay-per-download-reven

[52] Salz, P. A. (2014). The insider's guide to a billion dollar app business. Retrieved November 12, 2015, from: http://www.inmobi.com/ui/pdfs/apponomics.pdf

[53] Seufert. E. B. (2014). Freemium Economics: Leveraging Analytics and User Segmentation to Drive Revenue. 1st ed. Morgan Kaufmann Elsevier.

[54] App Annie, (2013). Freemium Apps are Exploding, Japan and China among growth leaders. Retrieved December 10, 2015, from: http://blog.appannie.com/freemium-apps-ios-google-play-japan-chinaleaders.

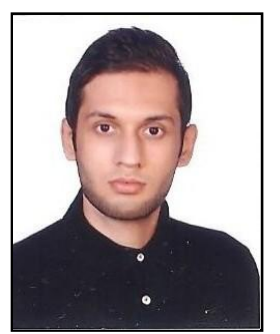

Sina Baghbaniyazdi received his master degree in Entrepreneurship from the University of Tehran, Iran in 2016 and his undergrad in banking management from the School of Science Economic-Iran in 2012. He is currently working in the Middle East Bank in Tehran, Iran. His research interests include mobile application marketing, online branding, ICT adoption \& diffusion and e-commerce-related adoption issues. His work has been published in journals like Reef Resources Assessment and Management 
Technical Paper and Iranian journal of management studies.

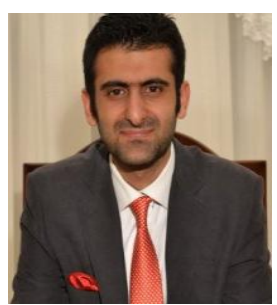

Hamed Ferdosara received MBA from University of Tehran and a BSc in mining Engineering from the IAU-Tehran South Branch. He is founder of "chibepoosham.com" and has worked in Badbadak (Mobile Value added Service), TGBS (IT solution), Tehran Municipality and Donya_e_Eqtesad newspaper as marketing manager and writer. His research interests are content and digital marketing. 